\title{
TNFa-Mediated Necroptosis in BBB Endothelia as a Potential Mechanism of Increased Seizure Susceptibility in Mice Following Systemic Inflammation
}

\author{
Wan-Yu Huang \\ National Cheng Kung University \\ Yen-Ling Lai \\ Changhua Christian Hospital \\ Ko-Hung Liu \\ Changhua Christian Hospital \\ Shankung Lin \\ Changhua Christian Hospital \\ Hsuan-Ying Chen \\ Changhua Christian Hospital \\ Chih-Hung Liang \\ Tunghai University \\ Hung-Ming Wu (D18288@cch.org.tw) \\ Changhua Christian Hospital https://orcid.org/0000-0003-4042-7132 \\ Kuei-Sen Hsu \\ National Cheng Kung University
}

\section{Research}

Keywords: Systemic inflammation, sepsis, seizure susceptibility, kainic acid, necroptosis, astrocyte kir4.1

Posted Date: October 12th, 2021

DOI: https://doi.org/10.21203/rs.3.rs-923098/v1

License: (c) (1) This work is licensed under a Creative Commons Attribution 4.0 International License. Read Full License 


\section{Abstract}

\section{Background}

Systemic inflammation is a potent contributor to increased seizure susceptibility. However, less is known about the effects of systemic inflammation on blood-brain barrier (BBB) that affect neuron excitability. Necroptosis and inflammation are intimately associated in various neurological diseases. We hypothesized that necroptosis is involved in the mechanism underlying sepsis-associated neuronal excitability in BBB components.

\section{Methods}

Systemic inflammation was induced by LPS. Seizure susceptibility of mice was measured by kainic acid intraperitoneal injection. Pharmacological inhibitors (C87 and GSK872) were used to block signaling of TNFa receptors and necroptosis. To identify the features of sepsis-associated response in the BBB and $\mathrm{CNS}$, brain tissues of mice were obtained for assays of the necroptosis-related protein expression, and immunofluorescence staining for morphological changes of endothelia and glia. Microdialysis assay was also used to evaluate the changes of extracellular potassium and glutamate levels in brain.

\section{Results}

Significant findings including induced increased seizure susceptibility and BBB endothelia necroptosis and leakage, Kir4.1 dysfunction, and microglia activation were observed in mice following LPS injection. Inhibition of TNFa receptor inhibitor C87 significantly attenuated increased kainic acid-induced seizure susceptibility and endothelia necroptosis and microglia activation, and restored kir4.1 protein expression, compared with those in controls. GSK872 (a RIP3 inhibitor) treatment, like C87, had consistent effects on these changes following LPS.

\section{Conclusions}

Our results showed that TNFa-mediated necroptosis in BBB endothelia damage contributes to the development of increased seizure susceptibility in mice after systemic inflammation. Pharmacologic inhibition targeting this necroptosis pathway may provide a promising therapeutic approach to reduce sepsis-associated BBB dysfunction, astrocyte ion channel dysfunction, and subsequent neuronal excitability.

\section{Introduction}

Seizure is a common acute complication of sepsis and systemic inflammation [1-3]. Seizure is provoked by the hyper-excitability of circuits within the brain, due to an imbalance between neuronal excitatory and inhibitory activities. Sepsis leading to the excessive production of proinflammatory factors in the peripheral system and brain is believed to be an important factor in the pathogenesis of neuronal hyperexcitation, leading to an enhanced predisposition to seizure, and subsequent changes of neuroplasticity, 
which may evolve into a chronic seizure syndrome [3-6]. Our previous study showed that a single intraperitoneal (i.p.) injection of lipopolysaccharide (LPS) in mice causes increased susceptibility to pentylenetetrazole-induced seizures [7]. Similar observations have been made in postnatal and adult animals $[3,6]$, including alterations to the number of neuronal receptors and changes to neuronal plasticity [8]. This evidence indicates that inflammatory processes initially from the peripheral system to brain are a common and crucial mechanism in the pathophysiology of seizures and epilepsy. However, the way in which unbalanced regulation of systemic inflammation contributes to seizure development is still unclear.

The blood-brain barrier (BBB) is a major part of the interface between the peripheral and central nervous systems (CNS). The BBB manages the exchange of blood and compounds between the brain and the circulation and maintains a stable CNS environment. It has long being proposed that dysfunction of the BBB may affect neuronal excitability or firing $[3,9,10]$. The BBB is composed of endothelial cells, tight junctions, basal lamina, and associated cells, including astrocytic end-feet and pericytes. The continuous non-fenestrated endothelial cells contribute in part to the restrictive permeability and control of leukocyte transmigration of the BBB via their inherent low pinocytic activity and their high concentration of efflux transporters [11]. A number of preclinical studies in vitro and in vivo have shown that inflammatory challenge results in an increase in the permeability of the BBB. The administration of cytokines, such as interleukin (IL)-1, tumor necrosis factor-a (TNFa), and IL-6, increases endothelial permeability $[12,13]$. Astrocytes also play a critical role in maintaining the homeostasis of the BBB with respect to neuroglial cells. Astrocyte end-feet contain several channel proteins, such as the inwardly rectifying potassium (Kir) channel subunit Kir4.1, one of the integral parts of the orthogonal arrays of particles, which are required to provide optimal BBB properties [11]. Kir 4.1 channels, specifically expressed in astrocytes, play a key role in controlling spatial $\mathrm{K}^{+}$concentration and regulating extracellular glutamate concentration at tripartite synapses $[14,15]$. Astrocytes, via channels such as Kir4.1, directly affect neural excitability and have been implicated in the pathogenesis of seizures and the development of epilepsy [14].

Necroptosis is a regulated necrosis, different from apoptosis and necrosis, and is mediated by death receptors such as TNFa receptor 1, receptor-interacting protein kinase (RIP)1, and RIP3, which activate the phosphorylation of mixed lineage kinase domain-like (MLKL) protein, disturbing the integrity of the cells $[16,17]$. The necroptosis pathway has been reported to serve a vital role in many pathologies that involve inflammatory processes, including sepsis, inflammatory bowel disease, and neurodegenerative diseases [18]. The necroptosis mechanism has attracted considerable research attention because of its importance in endothelial damage and BBB leakage after stroke $[19,20]$. However, there have been only a few reports that necroptotic cell death signaling occurs in these BBB components following systemic inflammation.

Sepsis and system inflammation induce the excessive production of proinflammatory factors and rapidly corresponding neuroinflammation [7], which may lead to BBB damage and subsequent leakage [13]. Necroptosis and inflammation are intimately associated. Therefore, we hypothesized that necroptosis links systemic inflammation inflammatory mediators such as TNFa, changes in BBB components such 
as endothelial cell and astrocytes, and BBB dysfunction, contributing to alteration in susceptibility to seizure. By using an LPS-induced systemic inflammation mouse model, we found for role of TNFamediated necroptosis in BBB changes, including endothelial damage and astrocytic Kir4.1 dysregulation, related to an increase in susceptibility to seizures in mice, following systemic inflammation.

\section{Materials And Methods}

\section{Animals and the LPS-induced systemic inflammation model}

Eight- to nine-week-old male C57BL/6J mice were purchased from the National Lab Animal Center (Taiwan). The animals were housed in a specific pathogen-free room at $21^{\circ} \mathrm{C}$ under a 12 -h light/12-h dark artificial lighting cycle, with free access to feed. Age- and weight-matched animals were used for the present experiments. All procedures were approved by the Animal Care and Use Committee of Changhua Christian Hospital. The mouse model of systemic inflammation was induced by an i.p. injection of $4 \mathrm{mg} / \mathrm{kg}$ LPS (Escherichia coli, strain 0111:B4, Calbiochem, San Diego, CA, USA), as previously described [7].

\section{Determination of susceptibility to seizure using kainic acid}

To assess susceptibility to seizure, mice were injected i.p. with 3 or $20 \mathrm{mg} / \mathrm{kg}$ kainic acid (KA) $72 \mathrm{~h}$ after treatment with LPS (Sigma, St. Louis, MO, USA) or vehicle (normal saline). KA is a common proconvulsant agent used for the induction of seizures. Seizure activity was recorded on video during an observation period of $2 \mathrm{~h}$ after KA injection. Behavioral seizures were scored according to a previously defined scale [21] as follows: stage 0 , no response; stage 1 , body position lowering and hypoactivity; stage 2, body automatic shaking, whisker twitching, and sudden muscle or tail contraction; stage 3 , repetitive scratching, head bobbing, or circling; stage 4, forelimb clonus and rearing and falling; stage 5, repetitive behavior of stage 4 ; and stage 6 , severe generalized tonic-clonic seizure. In the behavior test, we recorded the severity score according to the aforementioned criterion for each 5 min over a 120-min period.

\section{Plasma levels of TNFa after peritoneal administration of LPS}

To assess the acute effects of LPS on systemic inflammation with and without pretreatment with TNFa receptor inhibitor C87 and RIP3 kinase inhibitor GSK872, blood samples were obtained from the cheek of the mice $1 \mathrm{~h}$ after the i.p. injection of $4 \mathrm{mg} / \mathrm{kg}$ LPS. The plasma samples were stored at $-80^{\circ} \mathrm{C}$ until they were assayed for TNFa concentrations using Duo set kits (R\&D Systems, Minneapolis, MN, USA), according to the manufacturer's instructions.

\section{Western blotting analysis}

For protein lysate extraction, the dissected hippocampus was homogenized and lysed in ice-cold modified radioimmunoprecipitation assay buffer containing $150 \mathrm{mM} \mathrm{NaCl} ; 50 \mathrm{mM}$ Tris- $\mathrm{HCl}(\mathrm{pH}$ 7.4); 1 mM phenylmethylsulfonyl fluoride; $1 \%$ Nonidet P-40; 1 mM EDTA; $10 \mu \mathrm{g} / \mathrm{mL}$ each of 
leupeptin, aprotinin, and pepstatin; $1 \mathrm{mM} \mathrm{NaF}$; and $1 \mathrm{mM} \mathrm{Na}_{3} \mathrm{VO}_{4}$. Immunoblotting analysis was performed as previously described [7]. Briefly, $20-30 \mu \mathrm{g}$ of total protein was loaded per lane on $10 \%-15 \%$ polyacrylamide gels. The gels were transferred to polyvinylidene difluoride membranes, which were probed with antibodies against proteins including JNK (1:1000; \#9258, Cell Signaling, Danvers, MA, USA), Bax (1:1000; \#2772, Cell Signaling), cleaved Caspase 3 (1:500; Abcam Cambridge, UK; ab13847), RIP3 (1:1000; \#95702, Cell Signaling), RIP3 (phosphoS232) (1: 1000; ab195117, Abcam), MLKL (1:500; ab196436, Abcam), MLKL (Ser125) (1:500; PA5-105677, Invitrogen, CA, USA), TNFa (1:1000; \#11948, Cell Signaling), NKCC1 (1:1000; \#14581, Cell Signaling), KIR4.1 (1:500; sc-23637, Santa Cruz, CA, USA), and alpha-tubulin (1:1000; GTX628802, GeneTex, CA, USA), and beta-actin (1:2500; sc-47778, Santa Cruz) overnight at $4{ }^{\circ} \mathrm{C}$, followed by pairing different secondary antibodies with HRP-conjugated goat antimouse and goat anti-rabbit at dilution of 1:10,000. Signals were visualized and quantified using the GeneGnome chemiluminescence imaging system (Syngene, Bengaluru, India).

\section{Immunofluorescence staining}

Mice brains were harvested and soaked in $4 \%$ paraformaldehyde overnight and then dehydrated in $30 \%$ sucrose at $4^{\circ} \mathrm{C}$ for $48 \mathrm{~h}$. Serial $20-\mu \mathrm{m}$ cryosections were cut, washed 3 times with PBS, and then treated with sodium citrate buffer at $80^{\circ} \mathrm{C}$ for $30 \mathrm{~min}$. The cryosections were washed with PBS three times after cool down and permeabilized with $0.15 \%$ Triton X-100 (Thermo Fisher Scientific, MA, USA) in commercial blocking buffer at room temperature $\left(23^{\circ} \mathrm{C}-25^{\circ} \mathrm{C}\right)$ for $30 \mathrm{~min}$. The cryosections were hybridized with each primary antibody, including those against, Iba1 (1: 200; GTX100042, GeneTex), GFAP (1:500; GTX85454, GeneTex), MLKL (Ser125) (1:100; PA5-105677, Invitrogen;), Kir4.1 (1:250; sc-23637; Santa Cruz), CD31 (1: 800; ab24590, Abcam), and CD68 (1: 300; MAB1435, Merk Millipore, MA, USA), overnight at $4^{\circ} \mathrm{C}$ and then with different rhodamine- or Alexa-488-conjugated secondary antibodies, as previously described [7]. Sections were counterstained with DAPI to identify the cell nucleus. Microfluorescence images were taken using an Olympus microscope (Olympus DP80® Dual CCD Microscope, Tokyo, Japan).

Immunofluorescence images were used to analyze the staining density in the CA3 subregions using ImageJ software (NIH, Bethesda, MD, USA)[22]. The number of activated microglia and reactive astrocytes were counted using a stereological approach from three sections of the CA3 subregion in each hippocampus ( $\mathrm{n}=3$ mice per group), employing an Olympus DP80® Dual CCD Microscope, as previously described [23]. Briefly, images were captured from the CA3 subregion at -2.18 to $-2.54 \mathrm{~mm}$ from the bregma. The coordinates for the CA3 were taken from the 2.0 - to $3.0-\mathrm{mm}$ medial to lateral regions and the 2.0- to 3.2-mm dorsal to ventral regions. Activated microglia were distinguished from resting microglia by their amoeboid appearance and significant enlargement. Reactive astrocytes had a hypertrophic morphology distinct from that of resting astrocytes. A single experimenter, who was blind to each animal's treatment, performed the quantification of cells of interest using images taken at 200x magnification in selected rectangular regions.

\section{Brain interstitial fluid microdialysis}


Eight- to nine-week-old male C57BL/6J mice were used for brain microdialysis assays, using procedures modified from previous studies [24,25]. Mice were anesthetized with isoflurane for stereotaxic surgery to place a guide cannula (Plastics One, Roanoke, VA, USA) into the right hippocampus (anterior-posterior, $-2.3 \mathrm{~mm}$; medial-lateral, $2.0 \mathrm{~mm}$; and dorsal-ventral, $-2.0 \mathrm{~mm}$ relative to the bregma). One day postoperatively, mice $(\mathrm{n}=36)$ were treated with either vehicle $(0.25 \%$ DMSO) or $2 \mathrm{mg} / \mathrm{kg} \mathrm{GSK} 872$, and $1 \mathrm{~h}$ later treated with saline or $4 \mathrm{mg} / \mathrm{kg}$ LPS. Eighteen of these mice had CMA/12 probes (CMA/12 Elite, lengths $2 \mathrm{~mm}$, CMA, Stockholm, Sweden) inserted $2 \mathrm{~h}$ before GSK872 treatment and were placed in a Plexiglas dialysis chamber. Then, the $\mathrm{CMA} / 12$ probes were immediately perfused with Ringer's solution $\left(147 \mathrm{mM} \mathrm{Na}^{+}, 2.2 \mathrm{mM} \mathrm{Ca}^{+2}, 4 \mathrm{mM} \mathrm{K}^{+}, \mathrm{pH} 7.0\right)$ at a flow rate of $2 \mu \mathrm{L} / \mathrm{min}$, set to collect $60 \mu \mathrm{L}$ of dialysate every $30 \mathrm{~min}$ for $6 \mathrm{~h}$. Four days post-operatively, 18 more mice that had been treated with GSK872 and LPS had probes inserted into the placed guide cannulas to collect the dialysates once every $30 \mathrm{~min}$ for $2 \mathrm{~h}$ in each mouse. The extracellular $\mathrm{K}^{+}$concentrations of these dialysates were measured using a flame atomic absorption spectrometer (FAAS, Z6100 Hitachi, Japan). $\mathrm{K}^{+}$levels were calculated from a standard curve prepared from the standard solutions (Merck, Darmstadt, Germany). Glutamate concentrations were measured using an enzymatic colorimetric method using a microdialysis analyzer (CMA/600, Carnegie Medicin, Stockholm, Sweden).

\section{Statistical analysis}

The means of two groups were compared using Student's t-tests. The means of more than two groups were compared using one-way ANOVA, followed by Bonferroni post hoc tests. Differences in KA-induced seizure severity among treated mouse groups and extracellular potassium and glutamate changes among treated GSK872 mouse groups were assessed using two-way repeated measures ANOVA, adjusted using Bonferroni post hoc tests. Statistical analysis was performed using the GraphPad Prism version 7 software (GraphPad Software, San Diego, CA, USA, www.graphpad.com). All values are presented as mean \pm standard error of the mean (SEM). Differences were considered significant at $p<$ 0.05 .

\section{Results}

\section{LPS-induced systemic inflammation increased susceptibility to KA-induced seizure in mice}

To explore the mechanisms underlying the onset and development of seizures following systemic inflammation, our established animal model was used with a single $4-\mathrm{mg} / \mathrm{kg}$ dose of LPS via intraperitoneal injection to induce systemic inflammation in 8- to 9-week-old male mice [7]. Seizure susceptibility was subsequently determined by scoring the severity and duration of the KA-induced seizure every 5 min for a 2-h period (Fig. 1A). The mortality rate among the mice was approximately $12 \%$ within 3 days after LPS injection (Fig. 1B). During a 2-h period after KA injection, one of 13 saline-treated mice administered $20 \mathrm{mg} / \mathrm{kg} \mathrm{KA}$ and 2 out of 13 LPS-treated mice administered $3 \mathrm{mg} / \mathrm{kg} \mathrm{KA}$ died from severe seizures. Among the groups treated with saline and either 3 or $20 \mathrm{mg} / \mathrm{kg} \mathrm{KA}$ and the group treated with LPS and $3 \mathrm{mg} / \mathrm{kg} \mathrm{KA}$, two-way repeated measures ANOVA revealed that the main effect for these 
three groups yielded an $\mathrm{F}$ ratio value of $\mathrm{F}(2,900)=395.89, p<0.0001$ (Fig. 1C), indicating a significant difference in susceptibility to KA-induced seizure between these three groups. Bonferroni post hoc tests further revealed that there was a significant difference between the 3-mg/kg-KA-saline-treated group and 20 -mg $/ \mathrm{kg}$-KA-saline-treated group $(\mathrm{F}(1,600)=860.18 ; p<0.0001)$, but no difference between the 20$\mathrm{mg} / \mathrm{kg}-\mathrm{KA}$-saline-treated group and 3-mg/kg-KA- and LPS-treated groups $(\mathrm{F}(1,600)=1.17, p=0.285)$. These results indicated increased susceptibility to $3-\mathrm{mg} / \mathrm{kg}-\mathrm{KA}$ in LPS-treated mice $\mathrm{t}$ was similar to that in saline- and 20-mg/kg-KA-treated mice (Fig. 1C). The latency to initial seizure onset that was defined as seizure score stage 4 (i.e., tonic with or without clonic convulsion) or more after KA administration was significantly decreased in LPS-treated mice given $3 \mathrm{mg} / \mathrm{kg} \mathrm{KA}$, compared with that in saline-treated mice given $20 \mathrm{mg} / \mathrm{kg} \mathrm{KA}$ (Fig. 1D). All saline-treated mice administered $3 \mathrm{mg} / \mathrm{kg}$ were not observed to reached tonic with or without clonic convulsion. We measured the duration of stage 4-6 seizure among the mice receiving LPS or vehicle control with KA. The seizure duration was $40.00 \pm 5.31 \mathrm{~min}$ (mean \pm SEM) for the saline- and 20-mg/kg-KA-treated groups and $57.69 \pm 6.69 \mathrm{~min}$ for the LPS- and 3-mg/kg-KA-treated groups (Fig. 1E). The LPS-treated group had increased susceptibility to $3 \mathrm{mg} / \mathrm{kg} \mathrm{KA}$-induced seizures in the latency of initial seizure onset and seizure-behavior duration, compared with the 20-mg $/ \mathrm{kg}$-KA-treated mice without LPS injection.

\section{LPS-induced systemic inflammation induced programmed necroptosis and Kir4.1 dysregulation in the hippocampus}

We determined the role of several signaling pathways that could be involved in the mechanisms of neuronal hyper-excitability following systemic inflammation, including pathways involved in apoptosis, necroptosis, and ion channel changes [26, 27]. Seventy-two hours after injection with vehicle (saline) or 4 $\mathrm{mg} / \mathrm{kg}$ LPS, the mice were intraperitoneally administered vehicle $\left(\mathrm{H}_{2} \mathrm{O}\right)$ or $3 \mathrm{mg} / \mathrm{kg} \mathrm{KA}$. Two hours later, the hippocampus was obtained for the assessment of the expression of proteins involved in the apoptosis and necroptosis pathways, as well as astrocytic ion channels ( $\mathrm{n}=3$ mice per group) using Western blotting. Among these four groups of saline- or LPS-treated mice administered vehicle or KA, we found the protein levels of JNK, Bax, and cCaspase 3, which are part of the apoptosis pathway, were significantly increased by KA treatment, but no difference was found in mice treated with LPS alone (Fig. $2 A-2 D)$. The protein levels of phosphated RIP3 and phosphated MLKL, from the necroptosis pathway, were increased in LPS-treated mice, enhanced by KA treatment, compared with those in vehicle-treated mice (Fig. 2A, 2E and 2F). The levels of phosphated MLKL and TNFa were markedly enhanced after treatment with $3 \mathrm{mg} / \mathrm{kg} \mathrm{KA}$ (Fig. 2A and 2G). The protein levels of Kir4.1, but not NKCC1, were significantly decreased in LPS-treated mice, compared with those in vehicle-treated mice (Fig. $2 \mathrm{H}$ and 2I).

\section{Inhibition of either TNFa receptor or RIP3 attenuated the increased susceptibility to KA-induced seizure in mice following LPS injection}

TNFa is rapidly released and is one of the most abundant mediators of inflammation in the peripheral blood after infection or exposure to LPS [7]. TNFa has been implicated in the pathogenesis of several inflammation-related diseases, such as vascular leaks, via different signaling pathways [28]. On the basis 
of the aforementioned evidence (Fig. 2), TNFa-dependent necroptosis appeared to be involved in the increase of LPS-induced susceptibility to seizure. Therefore, the TNFa receptor inhibitor, C87, and the RIP3 inhibitor, GSK872, were used to explore the role of TNFa-dependent necroptosis on LPS-associated susceptibility to seizure. Mice were injected intraperitoneally with 2 doses of CS87 ( $2 \mathrm{mg} / \mathrm{kg}$, i.p.) at 1 and $24 \mathrm{~h}$, or one dose of GSK872 (2 mg/kg, i.p.) at $1 \mathrm{~h}$, before LPS injection (Fig. 3A). The mortality rate of the mice was approximately $12 \%$ within 3 days after the administration of LPS only, and no deaths were recorded in mice receiving either C87 or GSK872 with LPS treatment. Seventy-two hours after LPS injection, $3 \mathrm{mg} / \mathrm{kg} \mathrm{KA}$ was administered to evaluate the susceptibility to seizure of these mice $(n=7-10$ mice per group) by scoring once every $5 \mathrm{~min}$ for $2 \mathrm{~h}$. During a 2-h period after KA treatment, one of the 10 LPS-treated mice given KA died because of severe seizures; no death was observed in the LPS-treated groups given C87 $(n=10)$, or GSK872 $(n=10)$, as well as in saline-treated group $(n=7)$. Two-way repeated measures ANOVA revealed that the main effect for these four groups yielded an $F$ ratio of $F(3$, $825)=192.65, p<0.0001$ (Fig. 3B). Bonferroni post-tests analysis further revealed that there was a significant difference between the C87-treated group $(F(1,450)=273.49, p<0.0001)$ and the GSK872treated group $(F(1,450)=117.60, p<0.0001)$ from vehicle-treated mice following LPS injection. These results indicated that either $\mathrm{C} 87$ treatment or GSK872 treatment attenuated the susceptibility to KAinduced seizure following LPS injection. There was a significant difference between C87-treated mice and GSK872-treated mice $(F(1,450)=25.56, p<0.0001)$, indicating that C87 treatment was better than GSK872 treatment for decreasing seizure susceptibility in the LPS-treated mice. The latency to initial seizure onset (Fig. 3C) and seizure duration during a 2-h period (Fig. 3D) after KA administration (stage 4 or more) were significantly attenuated by either C87 or GSK872 treatment in LPS-treated mice, compared with those in vehicle-treated mice. Half of the mice treated with C87 and GSK872 were not observed to have tonic with or without clonic seizure (i.e., stage 4).

\section{Inhibition of TNFa receptor or RIP3-attenuated BBB leakage, endothelial necroptosis, and astrocytic Kir4.1 down-regulation in the hippocampus of mice treated with LPS}

To investigate the effect of the TNFa-dependent necroptosis signal pathway on the integrity of the BBB following LPS injection, we examined the effects of C87 and GSK872 treatment on BBB leakage and neuroinflammation. Mice were dosed with C87 at 24 and $1 \mathrm{~h}$ before LPS injection, or one dose of GSK872 at $1 \mathrm{~h}$ before LPS, or vehicle and then were sacrificed at $72 \mathrm{~h}$ after LPS treatment. Hippocampus sections were prepared for immunostaining with Iba- 1 antibody for microglia, CD68 antibody for monocytes, GFAP antibody for astrocytes, and Kir4.1 antibody for channel proteins. Activated microglia were identified by their increased cell size and irregular shape. The percentage of activated microglia (Fig. 4A and 4B) and leaked monocytes (Fig. 4C) in the CA3 regions of the hippocampus was significantly increased in the LPS-treated group, which was attenuated by pretreatment with either C87 or GSK872. Reactive astrocytes indicate the presence of hypertrophic morphology. The percentage of active astrocytes was significantly higher in the LPS-treated mice than in the C87- or GSK-872-treated mice (Fig. 4D and 4E). The proportion of GFAP-positive cells co-localized with Kir4.1 was constant in the control and KA-treated mice but markedly decreased in the LPS-treated mice (Fig. 4F). For determining the MLKL activity of BBB endothelial cells, immunostaining was performed using CD31 antibody for the endothelial cells and p- 
MLKL antibody for the bioactivity (Fig. 4G). The proportion of CD31-positive cells co-localized with pMLKL was lower in control mice, but markedly increased in LPS-treated mice (Fig. 4H). C87 and GSK872 pretreatment of LPS-treated mice reversed the phenomenon of enhanced p-MLKL-positive staining in BBB endothelial cells and decreased Kir4.1-positive staining in astrocytes.

\section{GSK872 suppressed RIP3-mediated necroptosis and restored Kir4.1 protein expression in mice within 3 days after LPS injection}

We examined the effects of GSK872 on dynamic changes in RIP3-mediated necroptosis and Kir4.1 protein within 3 days after induction by LPS. Mice were pretreated with GSK872 $(2 \mathrm{mg} / \mathrm{kg}$, i.p.) or vehicle (0.25\% DMSO) $1 \mathrm{~h}$ before LPS was given (Fig. 5A). The protein levels of the hippocampus were measured at 6,48 , and $72 \mathrm{~h}$ after LPS injection ( $n=3$ per group for each time point). The protein levels of $p$-RIP3 and p-MLKL were significantly higher (Fig. 5B-5D) and Kir4.1 protein levels were significantly lower than those given vehicle (Fig. 5B and 5E) at these time points within 3 days after LPS treatment. GSK872 treatment improved the RIP3-mediated necroptosis and the parallel decrease in expression of Kir4.1ion channel proteins.

\section{GSK872 attenuated increased levels of extracellular potassium and glutamate in the hippocampus within 3 days after LPS injection}

Microdialysis was used for continuous measurement of free and unbound analyte levels in the extracellular fluid in mice treated with GSK872 and LPS. One day after the cannula was implanted in the hippocampus, the mice were treated with GSK872 (2 mg/kg, i.p.) or vehicle $(0.25 \%$ DMSO, i.p.) $(n=6$ per group) $1 \mathrm{~h}$ before the administration of either saline or $4 \mathrm{mg} / \mathrm{kg}$ LPS (Fig. 6A). The mean of the first three samples immediately before LPS administration was defined as the basal levels (100\%) of extracellular potassium and glutamate in the hippocampus. Within $5 \mathrm{~h}$ after GSK872 and LPS injections, we found that the concentrations of extracellular potassium and glutamate had increased (Fig. 6B and 6C). Twoway repeated measures ANOVA revealed that the main effect for these three groups yielded an $\mathrm{F}$ ratio of $F(2,165)=28.66, p<0.0001$ on potassium levels (Fig. 5B) and $F(2,165)=24.31, p<0.0001$ on glutamate levels (Fig. $6 \mathrm{C}$ ). Bonferroni post-test analysis further revealed that there was a significant difference in potassium $(F(1,110)=25.87, p<0.0001)$ and glutamate levels $(F(1,110)=12.59, p=0.0006)$ in the GSK872-treated group compared with that in the vehicle-treated group following LPS injection. These findings indicated that GSK872 treatment attenuated the changes in the levels of these extracellular molecules induced by LPS. Microdialysis experiments were also performed in treated mice $(n=6$ per group) $72 \mathrm{~h}$ after LPS injection, with samples collected once every $30 \mathrm{~min}$ for $2 \mathrm{~h}$ from each mouse after $1 \mathrm{~h}$ stabilization. The mean levels of extracellular potassium (Fig. 6D) and glutamate (Fig. 6E) were significantly higher in the LPS-treated group than in the vehicle-treated group and GSK872-treated group. These results indicated that GSK872 treatment attenuated LPS-induced aggravated potassium and glutamate changes within 3 days after LPS injection.

\section{Discussion}


In this study, we consistently observed that sepsis and systemic inflammation is linked to increased seizure susceptibility into corresponding neuro-inflammation such as the activation of microglia and astroglia in the brain [3-5, 7]. We also demonstrated that the TNFa-dependent necroptosis signal pathway governed the changes to the integrity of the BBB, such as endothelial cell damage and astrocytic ion channel Kir4.1 dysregulation following systemic inflammation, leading to neuronal hyper-excitability and the induction of seizures.

Our previous study showed increased susceptibility to seizure induced by using the proconvulsant pentylenetetrazole in mice following LPS injection [7]. This phenomenon was further observed that the susceptibility to low-dose ( $3 \mathrm{mg} / \mathrm{kg}$, i.p.) KA-induced seizure in mice with LPS injection was similar but more severe in initial latency of seizure onset and tonic-clonic seizure duration than those in mice injected with a high dose (20 mg/kg, i.p.) of KA with saline injection (Fig. 1). These results indicate that systemic inflammation increased neuronal excitability, which in turn reduced the threshold at which seizures are initiated by proconvulsants, or induced the onset of seizures. Besides sepsis-induced neuroinflammation and the subsequent production in the brain of proconvulsive cytokines such as TNFa and IL-1 $\beta$, which may be involved in neuronal activity changes [7], the results of this study suggest that dysregulation of the ion channel Kir4.1 of astrocytes may play an important role in the underlying mechanism for changes in seizure threshold in LPS-treated mice. The inwardly rectifying $\mathrm{K}^{+}$channels, Kir4.1, are enriched on the processes of astrocytes surrounding the synapses and blood vessels of the BBB but not in neurons and oligodendrocytes in the brain [29]. In neuronal excitation, the astrocytic Kir4.1 channels play a major role in extracellular potassium $\left(\mathrm{K}^{+}\right)$buffering to maintain the homeostasis of the neuronal microenvironment [30]. Diminished Kir4.1 buffering capabilities, such as pharmacological or genetic inhibition and downregulation, may induce membrane hypo-polarization coupled to reduced glutamate clearance in astrocytes, leading to neuronal hyper-excitability [30,31]. Increasing evidence strongly suggests that astrocytic Kir4.1 channels are involved in the development of seizure and epilepsy (epileptogenesis) [14, $32,33]$. The present study found for the first time that down-regulation of Kir4.1 in astrocytes combined with increase of extracellular potassium and glutamate levels may be involved in the LPS-induced decreased seizure threshold in mice. Both in vitro and in vivo studies suggest that primary mediators of the inflammatory response, such IL-1 $\beta$, could have an effect on the down-regulation of Kir4.1 transcription and protein expression in astrocytes $[34,35]$. The present study further demonstrated that Kir4.1 dysregulation in astrocytes produced by systemic inflammation could be restored by the inhibition of the TNFa-mediated necroptosis signaling pathway on BBB endothelial cells.

The BBB helps to regulate the reciprocal periphery-to-brain exchange of molecules and immune cells and maintain a tightly stable microenvironment for the CNS. Dysfunction of the BBB destroys hemostasis, leading to the pathological development of seizure disorders and other neurological disorders [36, 37]. During systemic inflammation, the components of the BBB could be changed at histological and/or molecular levels [13]. Endothelial cells are key components of the BBB, and damage to these cells during systemic inflammation may contribute to barrier dysfunction, whereas the other BBB components, including astrocytes, pericytes, and microglia/macrophages, seem to play a little role in the LPS-mediated 
disruption of the BBB [38]. In the present study, pretreatment with TNFa receptor inhibitor C87 abolished BBB endothelial necroptosis with a parallel change in monocyte leakage and corresponding neuroinflammation, and Kir4.1 dysregulation. By excluding the possibility that C87 treatment might alleviate LPS-induced peripheral TNF-a levels (see Additional file 1), these results strongly indicate that proinflammatory TNFa is a key factor involved in endothelial cell damage in the BBB and changes in the permeability of the BBB in the event of systemic inflammation.

Upon binding to TNFa receptor 1, TNFa triggers a range of signal pathways to regulate bioactivity in various cell types and tissues. TNFa may therefore impact the BBB endothelial cells and other components [28]. Both in vitro and in vivo studies show that TNFa may induce endothelial cell injury and death via the apoptosis and necroptosis pathways $[39,40]$ and disrupt endothelial tight junction barriers via targeting different pathways, such as the NF-KB pathway [41, 42], increasing endothelial leakage. The present study found that both inhibition of TNFa receptor by C87 and RIP3 necroptosis by GSK872 significantly attenuated the increased seizure susceptibility in LPS-treated mice (Fig. 3), although there were significant differences between these two treatments. This phenomenon could be explained by the possibility that TNFa may more broadly target the components of the BBB. RIP3 inhibition might also affect apoptosis in some situations, due to the possibility of cross-talk between necroptosis and apoptosis [43]. Given that our data showed that LPS did not increase the level of cCasp3 in mouse brains $72 \mathrm{~h}$ after injection (Fig. 2A and 2D), the contribution of LPS-triggered apoptotic death of BBB endothelium following necroptosis to the disruption of BBB integrity, if any, could be not significant. Therefore, among the signaling pathways involving TNFa, our data suggest that endothelial necroptosis plays a critical role in changes of seizure susceptibility in the context of TNFa-induced inflammatory events, including astrocytic ionic Kir4.1 channels and BBB dysfunction.

TNFa production peaked in the peripheral circulating blood at $1 \mathrm{~h}$ after LPS injection [7] and in the brain at approximately $30 \mathrm{~h}$ [44]. Evans Blue-measured BBB leakage was observed early, within $6 \mathrm{~h}$ after LPS injection (see Additional file 2), which corresponded to the finding of increased RIP3-mediated necroptosis (Fig. 5) and extracellular $\mathrm{K}^{+}$and glutamate within $4 \mathrm{~h}$ after LPS injection (Fig. 6). The results support the contention that systemic TNFa is an early and key peripheral proinflammatory factor causing BBB disruption during systemic inflammation but could not completely exclude the effects of the TNFa derived from microglia [19]. In the CNS, the levels of TNFa consistently returned to the basal levels by 72 $\mathrm{h}$ after LPS (Fig. 2G). KA treatment could not raise the brain levels of TNFa but rapidly increased TNFa levels (Fig. 2G) $[45,46]$ and enhanced the activity of MLKL in necroptosis in mice $72 \mathrm{~h}$ after LPS injection (Fig. 2F). Although the detailed mechanisms of this phenomenon remain incompletely understood, severe seizures may induce brain injury via a process of necroptosis involving MLKL [47]. These results suggest that a seizure threshold low enough to easily induce severe seizure in LPS-treated mice and increased levels of TNFa after KA treatment may play a role in additional MLKL-executed necroptosis in the brain (Fig. 2F).

Necroptosis is a type of programmed cell death with necrosis and is involved in a variety of biological processes, including inflammation and immune responses. Accumulating evidence suggests that the 
TNFa-mediated necroptotic pathway may be a potential therapeutic target in the treatment of inflammatory diseases $[48,49]$. Over the past years, several types of inhibitors targeting the kinase activity of necroptosis, such as RIP3, have been reported $[49,50]$. In the present study, GSK872, an RIP3 inhibitor, reduced the phosphorylation of MLKL and the programmed necrosis of BBB endothelial cells, supporting the suggestion that necroptosis could be a therapeutic target in efforts to prevent BBB damage from systemic inflammation. RIP3 is indispensable in the TNFa-stimulated necroptosis pathway and can also promote non-necroptotic pathways such as inflammation activation and cytokine IL-1 $\beta$ production through stimulation of Toll-like receptors [48]. Therefore, the effects of RIP3 inhibition on improvement of seizure susceptibility related to systemic inflammation could be partially due to nonnecroptotic anti-inflammation, even though MLKL activation in BBB endothelial cells was significantly attenuated in our observations. It will be important to further determine which RIP3 function drives the signaling pathways, such as those of inflammation and necroptosis, in each disease condition. In the future, studies exploiting more specific inhibitors of RIP3 and MLKL kinases may provide crucial insight into the prevention of necroptosis-associated BBB damage and neuroinflammation following sepsis.

\section{Conclusions}

Our results showed that TNFa-mediated necroptosis induced BBB endothelial damage and BBB leakage, leading to neuroinflammation and astrocyte Kir4.1 dysregulation and contributing to the development of increased susceptibility to seizure induced by KA in mice, following LPS-induced systemic inflammation. Pharmacologic inhibition targeting elements of the necroptosis pathway, such as TNFa receptor and RIP3 kinases, reduces BBB endothelial cell damage and BBB dysfunction. This evidence may indicate a promising therapeutic approach to reduce sepsis-associated BBB dysfunction, astrocyte ion channel dysfunction, and subsequent neuronal excitability.

\section{Abbreviations}

BBB, blood-brain barrier; LPS, lipopolysaccharide; TNFa, tumor necrosis factor-a; i.p., intraperitoneal; CNS, central nervous systems; IL, interleukin; Kir, inwardly rectifying potassium; RIP, receptor-interacting protein kinase; MLKL, mixed lineage kinase domain-like; KA, kainic acid.

\section{Declarations}

\section{Acknowledgments}

We thank Chew-Teng Kor PhD. Department of Internal Medicine, Changhua Christian Hospital for her valuable help in data analysis.

\section{Funding}

This study was supported by the grant MOST 108-2314-B-371-004-MY3 from the Ministry of Science and Technology, Taiwan and by the grant 108-CCH-IRP-129 from Changhua Christian Hospital. 
Availability of data and materials

The datasets supporting the conclusions of this article are included within the article and its Additional files. All material used in this manuscript will be made available to researchers subject to confidentiality.

\section{Authors' contributions}

YLL, KHL, HYC, SL and CHL performed the experiments. HMW and KSH designed the study, and WYH analyzed the data and wrote the manuscript. All authors read and approved the final manuscript.

\section{Ethics approval and consent to participate}

The experiments were approved by the Animal Care and Use Committee of Changhua Christian Hospital, and the experiments were performed according to the Guide for the Care and Use of Laboratory Animals of the National Institutes of Health of the United States.

\section{Consent for publication}

Not applicable.

\section{Competing interests}

The authors declare that they have no competing interests.

\section{References}

1. Sonneville R, Verdonk F, Rauturier C, Klein IF, Wolff M, Annane D, Chretien F, Sharshar T. Understanding brain dysfunction in sepsis. Ann Intensive Care. 2013;3:15.

2. Idro R, Gwer S, Kahindi M, Gatakaa H, Kazungu T, Ndiritu M, Maitland K, Neville BG, Kager PA, Newton $\mathrm{CR}$. The incidence, aetiology and outcome of acute seizures in children admitted to a rural Kenyan district hospital. BMC Pediatr. 2008;8:5.

3. Rana A, Musto AE. The role of inflammation in the development of epilepsy. J Neuroinflammation. 2018;15:144.

4. Riazi K, Galic MA, Pittman QJ. Contributions of peripheral inflammation to seizure susceptibility: cytokines and brain excitability. Epilepsy Res. 2010;89:34-42.

5. Cerri C, Genovesi S, Allegra M, Pistillo F, Puntener U, Guglielmotti A, Perry VH, Bozzi Y, Caleo M. The Chemokine CCL2 Mediates the Seizure-enhancing Effects of Systemic Inflammation. J Neurosci. 2016;36:3777-88.

6. Galic MA, Riazi K, Heida JG, Mouihate A, Fournier NM, Spencer SJ, Kalynchuk LE, Teskey GC, Pittman QJ. Postnatal inflammation increases seizure susceptibility in adult rats. J Neurosci. 2008;28:690413. 
7. Huang WY, Lin S, Chen HY, Chen YP, Chen TY, Hsu KS, Wu HM. NADPH oxidases as potential pharmacological targets against increased seizure susceptibility after systemic inflammation. J Neuroinflammation. 2018;15:140.

8. Harre EM, Galic MA, Mouihate A, Noorbakhsh F, Pittman QJ. Neonatal inflammation produces selective behavioural deficits and alters $\mathrm{N}$-methyl-D-aspartate receptor subunit mRNA in the adult rat brain. Eur J Neurosci. 2008;27:644-53.

9. Cornford EM, Oldendorf WH. Epilepsy and the blood-brain barrier. Adv Neurol. 1986;44:787-812.

10. Kovacs R, Heinemann U, Steinhauser C. Mechanisms underlying blood-brain barrier dysfunction in brain pathology and epileptogenesis: role of astroglia. Epilepsia. 2012;53(Suppl 6):53-9.

11. Lecuyer MA, Kebir H, Prat A. Glial influences on BBB functions and molecular players in immune cell trafficking. Biochim Biophys Acta. 2016;1862:472-82.

12. Rochfort KD, Cummins PM. The blood-brain barrier endothelium: a target for pro-inflammatory cytokines. Biochem Soc Trans. 2015;43:702-6.

13. Varatharaj A, Galea I. The blood-brain barrier in systemic inflammation. Brain Behav Immun. 2017;60:1-12.

14. Ohno Y, Tokudome K, Kunisawa N, Iha HA, Kinboshi M, Mukai T, Serikawa T, Shimizu S. Role of astroglial Kir4.1 channels in the pathogenesis and treatment of epilepsy. Therapeutic Targets for Neurological Diseases. 2015;2:e476.

15. Olsen ML, Sontheimer H. Functional implications for Kir4.1 channels in glial biology: from $\mathrm{K}+$ buffering to cell differentiation. J Neurochem. 2008;107:589-601.

16. Newton K, Manning G. Necroptosis and Inflammation. Annu Rev Biochem. 2016;85:743-63.

17. Dhuriya YK, Sharma D. Necroptosis: a regulated inflammatory mode of cell death. J Neuroinflammation. 2018;15:199.

18. Choi ME, Price DR, Ryter SW, Choi AMK. Necroptosis: a crucial pathogenic mediator of human disease. JCl Insight 2019, 4.

19. Chen AQ, Fang Z, Chen XL, Yang S, Zhou YF, Mao L, Xia YP, Jin HJ, Li YN, You MF, et al. Microgliaderived TNF-alpha mediates endothelial necroptosis aggravating blood brain-barrier disruption after ischemic stroke. Cell Death Dis. 2019;10:487.

20. Zille M, Ikhsan M, Jiang Y, Lampe J, Wenzel J, Schwaninger M. The impact of endothelial cell death in the brain and its role after stroke: A systematic review. Cell Stress. 2019;3:330-47.

21. Morrison RS, Wenzel HJ, Kinoshita Y, Robbins CA, Donehower LA, Schwartzkroin PA. Loss of the p53 tumor suppressor gene protects neurons from kainate-induced cell death. J Neurosci. 1996;16:133745.

22. Schneider CA, Rasband WS, Eliceiri KW. NIH Image to ImageJ: 25 years of image analysis. Nat Methods. 2012;9:671-5.

23. Huang WY, Liu KH, Lin S, Chen TY, Tseng CY, Chen HY, Wu HM, Hsu KS. NADPH oxidase 2 as a potential therapeutic target for protection against cognitive deficits following systemic inflammation 
in mice. Brain Behav Immun. 2020;84:242-52.

24. Tao K, Cai Q, Zhang X, Zhu L, Liu Z, Li F, Wang Q, Liu L, Feng D. Astrocytic histone deacetylase 2 facilitates delayed depression and memory impairment after subarachnoid hemorrhage by negatively regulating glutamate transporter-1. Ann Transl Med. 2020;8:691.

25. Chen HY, Cheng FC, Pan HC, Hsu JC, Wang MF. Magnesium enhances exercise performance via increasing glucose availability in the blood, muscle, and brain during exercise. PLoS One. 2014;9:e85486.

26. Mao XY, Zhou HH, Jin WL. Redox-Related Neuronal Death and Crosstalk as Drug Targets: Focus on Epilepsy. Front Neurosci. 2019;13:512.

27. Devinsky O, Vezzani A, Najjar S, De Lanerolle NC, Rogawski MA. Glia and epilepsy: excitability and inflammation. Trends Neurosci. 2013;36:174-84.

28. Blaser H, Dostert C, Mak TW, Brenner D. TNF and ROS Crosstalk in Inflammation. Trends Cell Biol. 2016;26:249-61.

29. Higashi K, Fujita A, Inanobe A, Tanemoto M, Doi K, Kubo T, Kurachi Y. An inwardly rectifying K(+) channel, Kir4.1, expressed in astrocytes surrounds synapses and blood vessels in brain. Am J Physiol Cell Physiol. 2001;281:C922-31.

30. Kucheryavykh YV, Kucheryavykh LY, Nichols CG, Maldonado HM, Baksi K, Reichenbach A, Skatchkov SN, Eaton MJ. Downregulation of Kir4.1 inward rectifying potassium channel subunits by RNAi impairs potassium transfer and glutamate uptake by cultured cortical astrocytes. Glia. 2007;55:27481.

31. Djukic B, Casper KB, Philpot BD, Chin LS, McCarthy KD. Conditional knock-out of Kir4.1 leads to glial membrane depolarization, inhibition of potassium and glutamate uptake, and enhanced short-term synaptic potentiation. J Neurosci. 2007;27:11354-65.

32. Ohno Y. Astrocytic Kir4.1 potassium channels as a novel therapeutic target for epilepsy and mood disorders. Neural Regen Res. 2018;13:651-2.

33. Inyushin M, Kucheryavykh LY, Kucheryavykh YV, Nichols CG, Buono RJ, Ferraro TN, Skatchkov SN, Eaton MJ. Potassium channel activity and glutamate uptake are impaired in astrocytes of seizuresusceptible DBA/2 mice. Epilepsia. 2010;51:1707-13.

34. Zurolo E, de Groot M, lyer A, Anink J, van Vliet EA, Heimans JJ, Reijneveld JC, Gorter JA, Aronica E. Regulation of Kir4.1 expression in astrocytes and astrocytic tumors: a role for interleukin-1 beta. J Neuroinflammation. 2012;9:280.

35. Nwaobi SE, Cuddapah VA, Patterson KC, Randolph AC, Olsen ML. The role of glial-specific Kir4.1 in normal and pathological states of the CNS. Acta Neuropathol. 2016;132:1-21.

36. van Vliet EA, da Costa Araujo S, Redeker S, van Schaik R, Aronica E, Gorter JA. Blood-brain barrier leakage may lead to progression of temporal lobe epilepsy. Brain. 2007;130:521-34.

37. Marchi N, Tierney W, Alexopoulos AV, Puvenna V, Granata T, Janigro D. The etiological role of bloodbrain barrier dysfunction in seizure disorders. Cardiovasc Psychiatry Neurol. 2011;2011:482415. 
38. Banks WA, Gray AM, Erickson MA, Salameh TS, Damodarasamy M, Sheibani N, Meabon JS, Wing EE, Morofuji Y, Cook DG, Reed MJ. Lipopolysaccharide-induced blood-brain barrier disruption: roles of cyclooxygenase, oxidative stress, neuroinflammation, and elements of the neurovascular unit. $J$ Neuroinflammation. 2015;12:223.

39. Li JH, Pober JS. The cathepsin B death pathway contributes to TNF plus IFN-gamma-mediated human endothelial injury. J Immunol. 2005;175:1858-66.

40. Zelic M, Roderick JE, O'Donnell JA, Lehman J, Lim SE, Janardhan HP, Trivedi CM, Pasparakis M, Kelliher MA. RIP kinase 1-dependent endothelial necroptosis underlies systemic inflammatory response syndrome. J Clin Invest. 2018;128:2064-75.

41. Clark PR, Kim RK, Pober JS, Kluger MS. Tumor necrosis factor disrupts claudin-5 endothelial tight junction barriers in two distinct NF-kappaB-dependent phases. PLoS One. 2015;10:e0120075.

42. Elahy M, Jackaman C, Mamo JC, Lam V, Dhaliwal SS, Giles C, Nelson D, Takechi R. Blood-brain barrier dysfunction developed during normal aging is associated with inflammation and loss of tight junctions but not with leukocyte recruitment. Immun Ageing. 2015;12:2.

43. Moriwaki K, Chan FK. The Inflammatory Signal Adaptor RIPK3: Functions Beyond Necroptosis. Int Rev Cell Mol Biol. 2017;328:253-75.

44. Erickson MA, Banks WA. Cytokine and chemokine responses in serum and brain after single and repeated injections of lipopolysaccharide: multiplex quantification with path analysis. Brain Behav Immun. 2011;25:1637-48.

45. Lehtimaki KA, Peltola J, Koskikallio E, Keranen T, Honkaniemi J. Expression of cytokines and cytokine receptors in the rat brain after kainic acid-induced seizures. Brain Res Mol Brain Res. 2003;110:253-60.

46. Ravizza T, Vezzani A. Pharmacological targeting of brain inflammation in epilepsy: Therapeutic perspectives from experimental and clinical studies. Epilepsia Open. 2018;3:133-42.

47. Cai Q, Gan J, Luo R, Qu Y, Li S, Wan C, Mu D. The role of necroptosis in status epilepticus-induced brain injury in juvenile rats. Epilepsy Behav. 2017;75:134-42.

48. Liu Y, Liu T, Lei T, Zhang D, Du S, Girani L, Qi D, Lin C, Tong R, Wang Y. RIP1/RIP3-regulated necroptosis as a target for multifaceted disease therapy (Review). Int J Mol Med. 2019;44:771-86.

49. Chen J, Kos R, Garssen J, Redegeld F. Molecular Insights into the Mechanism of Necroptosis: The Necrosome As a Potential Therapeutic Target. Cells 2019, 8.

50. Fauster A, Rebsamen M, Huber KV, Bigenzahn JW, Stukalov A, Lardeau CH, Scorzoni S, Bruckner M, Gridling M, Parapatics K, et al. A cellular screen identifies ponatinib and pazopanib as inhibitors of necroptosis. Cell Death Dis. 2015;6:e1767.

\section{Figures}




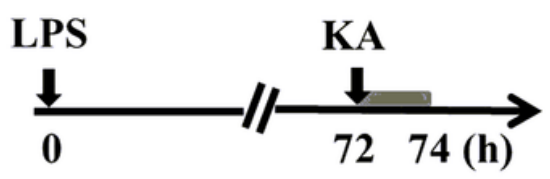

Seizure behavior observation
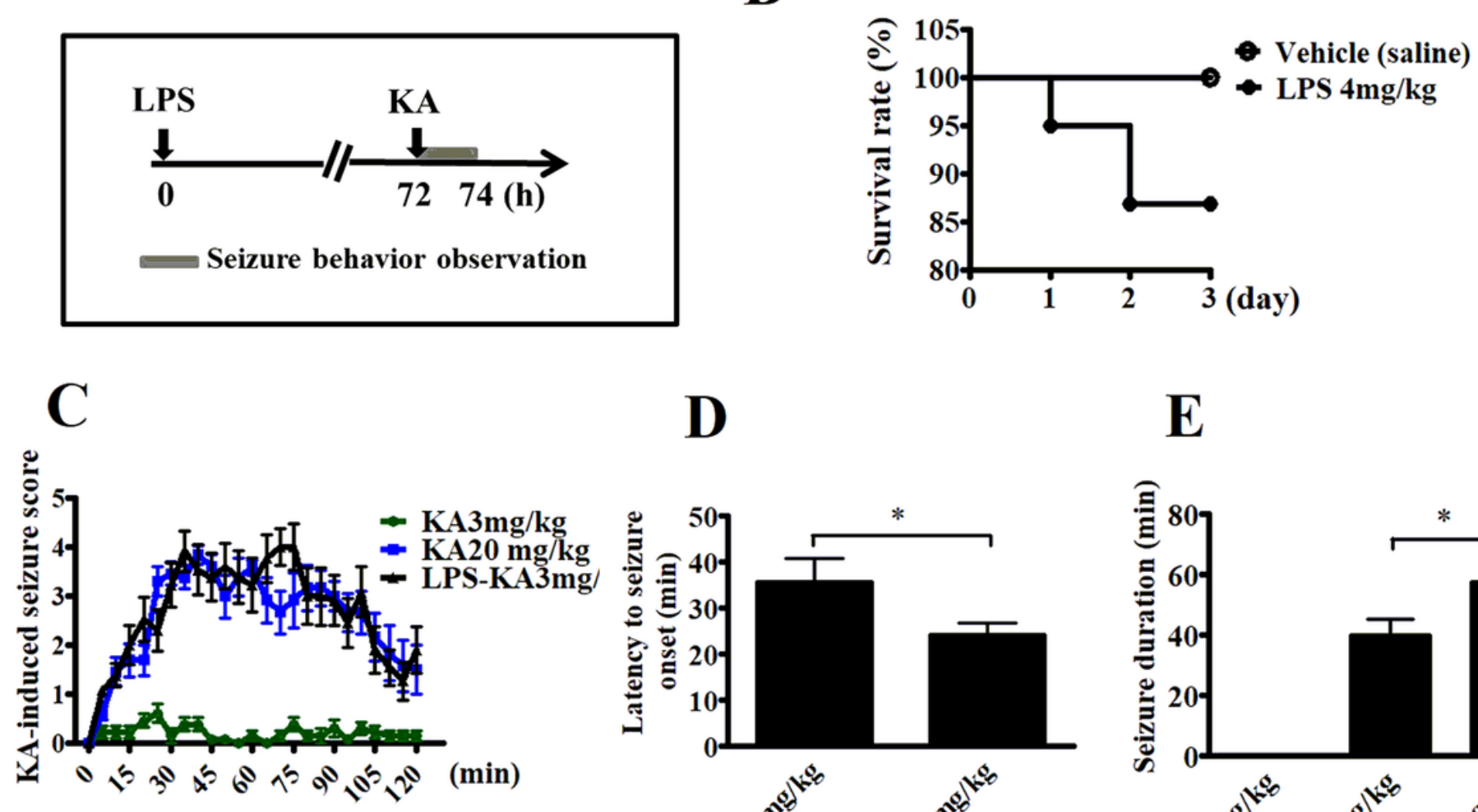

D

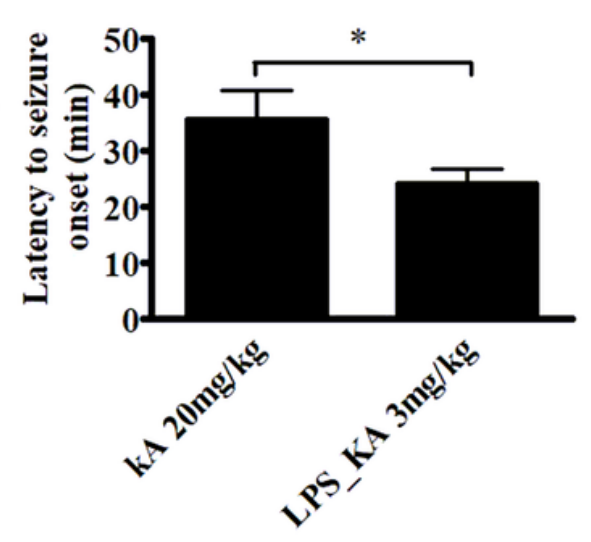

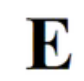

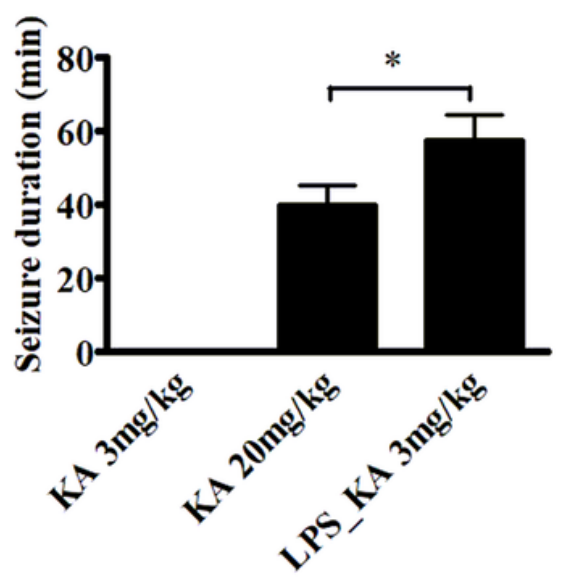

\section{Figure 1}

Increased seizure susceptibility to kainic acid in mice following LPS-induced systemic inflammation. (A) The experimental protocol. Mice were injected intraperitoneally with vehicle (normal saline) or $4 \mathrm{mg} / \mathrm{kg}$ lipopolysaccharide (LPS). Three days later, seizure susceptibility to kainic acid (KA) administered intraperitoneally was evaluated. (B) The mortality rate of mice within 3 days after LPS or vehicle injection. (C) Seizure susceptibility of these mice was scored once every 5 min over the 2-h period following injection with 3 or $20 \mathrm{mg} / \mathrm{kg} \mathrm{KA}$ ( $\mathrm{n}=13$ mice per group). Two-way repeated measures ANOVA revealed the main effect for these three groups including the LPS- and 3-mg/kg-KA-treated mice, and saline-treated mice with either 3 or $20 \mathrm{mg} / \mathrm{kg} \mathrm{KA}$ treatment yielded an $\mathrm{F}$ ratio of $F(2,900)=395.89, p<0.0001$; Bonferroni post-test analysis further revealed that there was a significant difference between the 3$\mathrm{mg} / \mathrm{kg}$-KA-saline-treated group and 20-mg/kg-KA-saline-treated group $(F(1,600)=860.18 ; p<0.0001)$ and between the 20-mg/kg-KA-saline-treated group and 3-mg/kg-KA- and LPS-treated groups $(F(1,600)=$ $1.17, p=0.285$ ). (D) The latency to initial seizure onset of stage 4 (i.e., tonic with or without clonic convulsion) or more after KA injection. Data are presented as mean \pm SEM. Student's t-test; ${ }^{*} p<0.05$. (E) The total duration (min) of seizure behavior of stage 4 or more. Data are presented as mean \pm SEM. Student's t-test; 3-mg/kg-KA- and LPS-treated group vs. $20-\mathrm{mg} / \mathrm{kg}-\mathrm{KA}$ - and saline-treated group; ${ }^{*} \mathrm{p}<0.05$. 


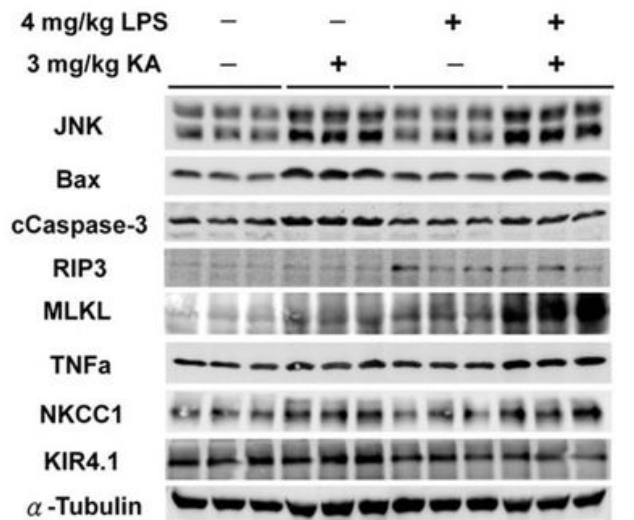

E

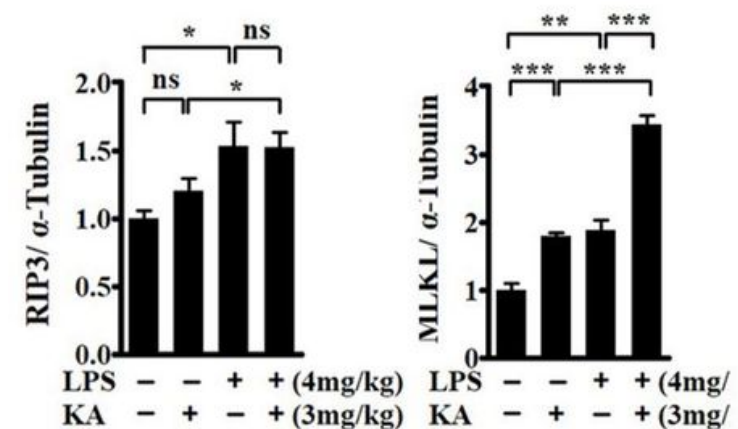

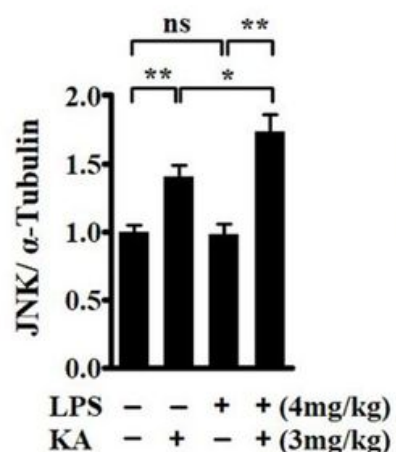
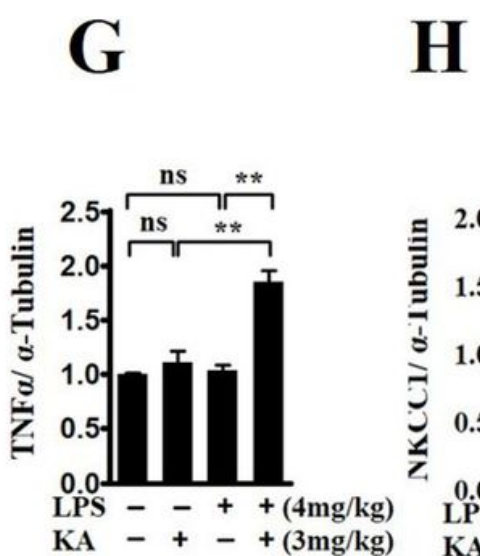

H
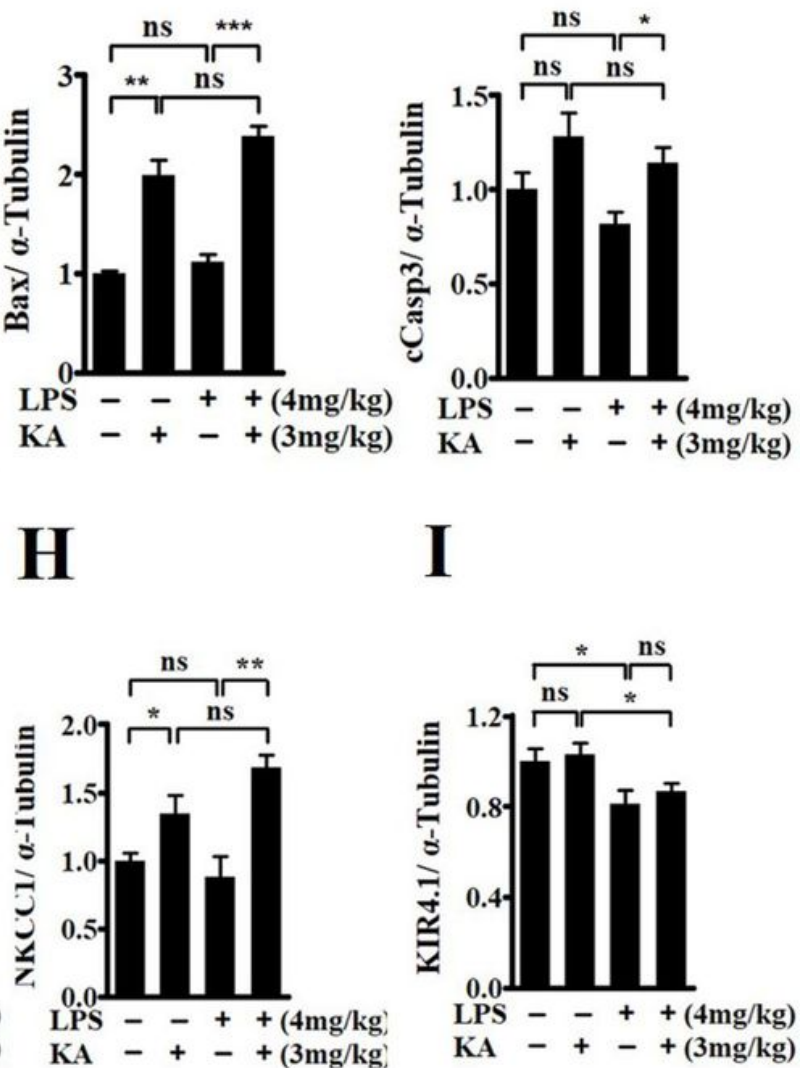

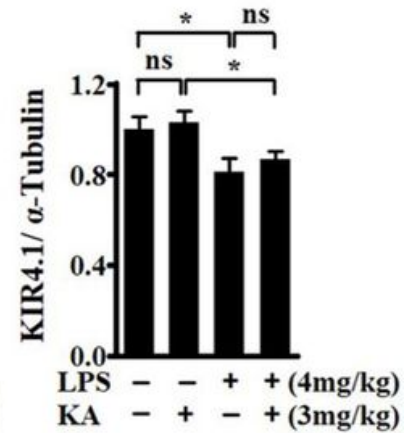

Figure 2

LPS-induced systemic inflammation induced the programmed necroptosis pathway and Kir4.1 dysregulation in the hippocampus. Three days after LPS or vehicle (saline) injection, $3 \mathrm{mg} / \mathrm{kg} \mathrm{kainic}$ acid or vehicle $(\mathrm{H} 2 \mathrm{O})$ was intraperitoneally administrated to the mice. Two hours later, the hippocampus was obtained for assessing the protein expression ( $n=3$ per group) using Western blots. (A) A representative Western blot showing the specific bands for these proteins. An equal amount of protein sample (30 $\mu \mathrm{g})$ obtained from the hippocampus homogenate was applied to each lane, and a-tubulin protein was used as an internal control. (B-D) Bar graph showing the densitometric analysis of the molecules JNK, Bax, and cCaspase 3 involved in the apoptotic pathway; $(E-G)$ of the proteins phosphated RIP3, phosphated MLKL, and TNFa in the necroptosis pathway; and ( $\mathrm{H}$ and $\mathrm{I})$ of the proteins NCKK1 and Kir4.1 in ion channels, normalized to a-tubulin expression. Each bar represents the mean \pm SEM. One-way ANOVA; Bonferroni post hoc test among the groups; ${ }^{\star} p<0.05$, ${ }^{\star *} p<0.01$, and ${ }^{* \star *} p<0.001$. 
A

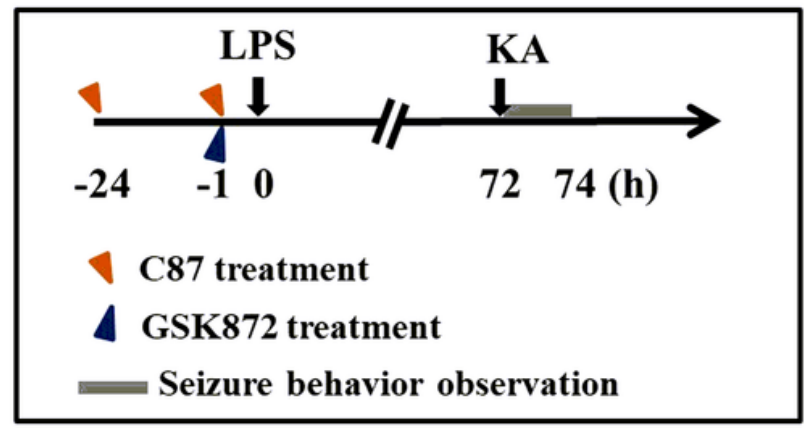

C

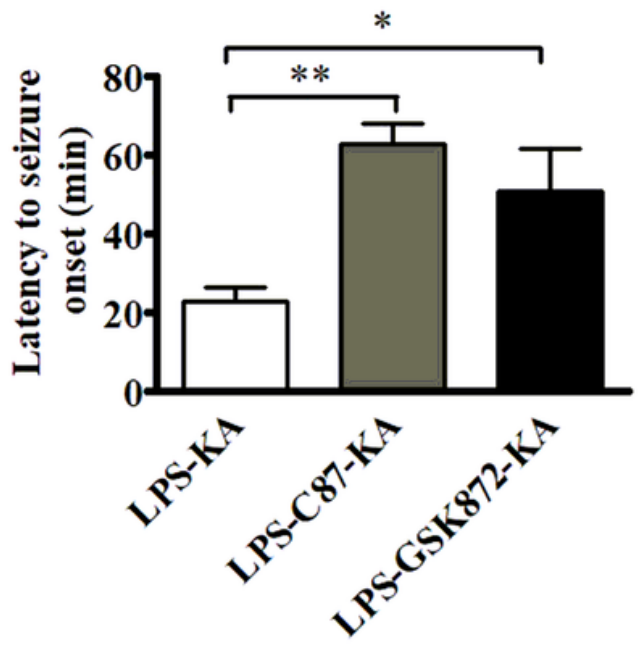

B

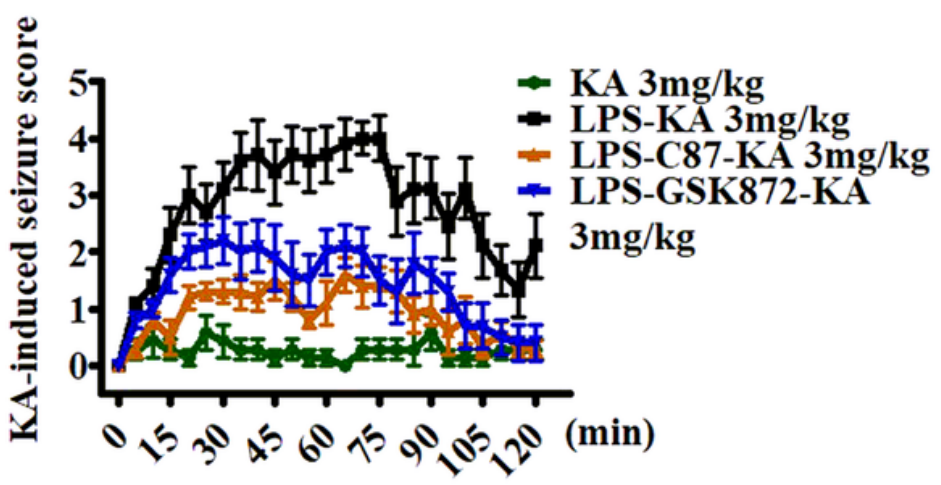

D

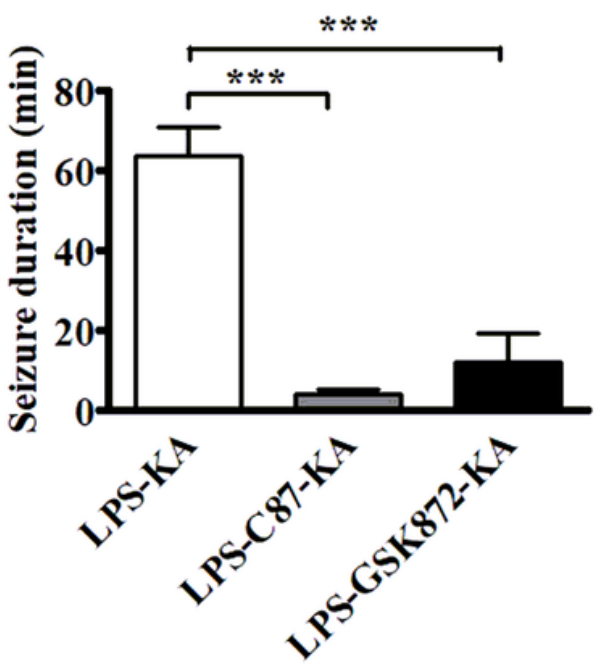

Figure 3

Inhibition of TNFa receptor and RIP3 attenuated increased kainic acid seizure susceptibility in mice following LPS injection. (A) The experimental protocol. Mice were injected intraperitoneally with 12.5 $\mathrm{mg} / \mathrm{kg}$ C87 given at 24 and $1 \mathrm{~h}$ before $4 \mathrm{mg} / \mathrm{kg}$ LPS i.p. injection or with $2 \mathrm{mg} / \mathrm{kg}$ GSK872 $1 \mathrm{~h}$ before LPS injection. Three days later, seizure susceptibility to $3 \mathrm{mg} / \mathrm{kg}$ kainic acid (KA) was evaluated $(\mathrm{n}=7-10$ mice per group). (B) Seizure susceptibility of treated mice scored once every 5 min over the 2-h period following KA injection. Using two-way repeated measures ANOVA analysis, Bonferroni post hoc analysis revealed that there was a significant difference between C87-treated mice $(F(1,450)=273.49, p<0.0001)$ and GSK872-treated mice $(F(1,450)=117.60, p<0.0001)$ from vehicle-treated mice following LPS injection, and between C87- and GSK872-treated mice $(F(1,450)=25.56, p<0.0001)$. (C) Latency to initial seizure onset (tonic with or without clonic convulsion) after KA administration. Data are presented as mean \pm SEM. One-way ANONA; Bonferroni post hoc test vs. vehicle- and LPS-treated groups; ${ }^{\star} p<0.05$, $\star \star p<0.01$. (D) The total duration (min) of seizure behavior of stage 4 or more. Data are presented as mean \pm SEM. One-way ANONA; Bonferroni post hoc test vs. vehicle- and LPS-treated groups; $* \star \star p<0.001$. 


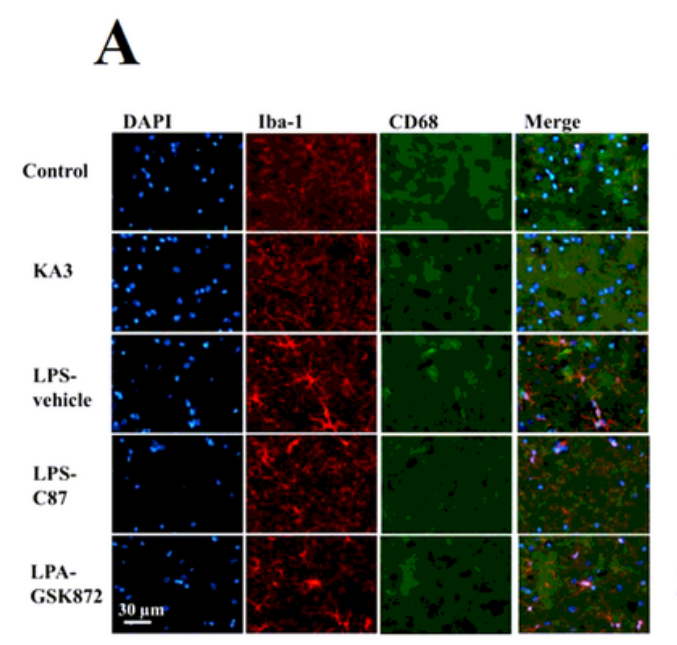

D
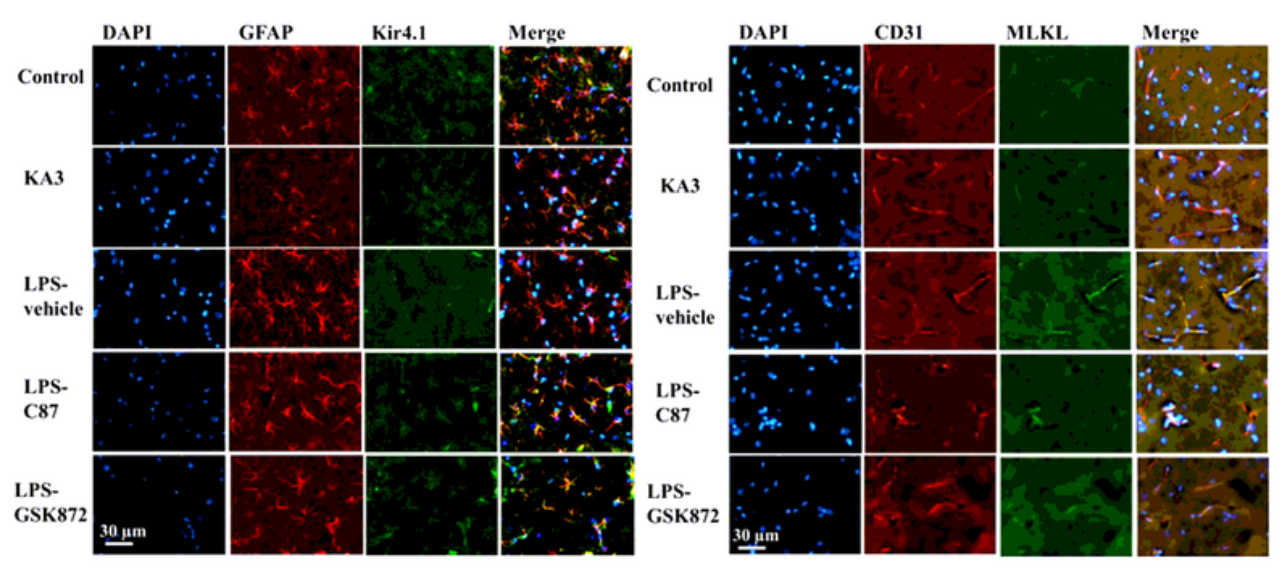

B

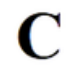

$\mathbf{E}$
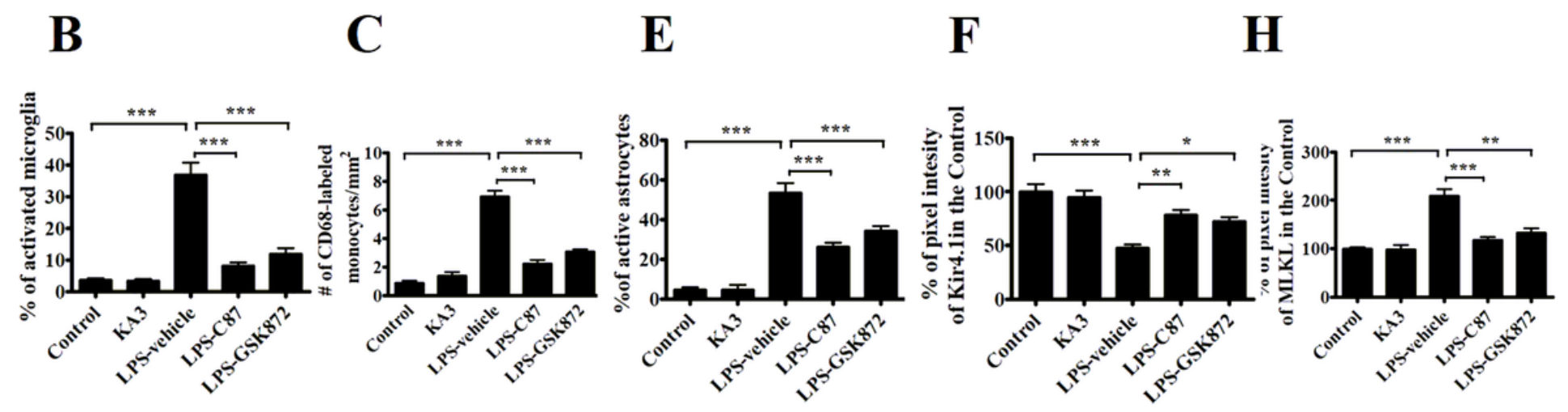

Figure 4

Inhibition of TNFa receptor and RIP3 attenuated BBB leakage and endothelial cell MLKL activity, and down-regulated KIR4.1 expression. Mice were treated with 2 doses of TNFa receptor C87 or vehicle at 24 and $1 \mathrm{~h}$ before $4 \mathrm{mg} / \mathrm{kg}$ LPS injection (i.p.), or with RIP3 inhibitor GSK872 $1 \mathrm{~h}$ before LPS was given, and then sacrificed $72 \mathrm{~h}$ after LPS administration. Hippocampal tissues of these mice were prepared for immunostaining ( $n=3$ per group). (A) Representative images of microglia stained with Iba- 1 and monocytes stained with CD68 in the CA3 region of the hippocampus. Increased cell size and irregular shape identified as the activated microglia. (B) The proportions of activated microglia and (C) the number/mm2 of CD68-positive cells in the CA3 of the hippocampus were estimated. (D) Representative images of astrocytes stained with GFAP and Kir4.1. Hypertrophic morphology identified as the activated astrocytes. (E) The proportions of activated GFAP-positive astrocytes and (F) the densitometric analysis of Kir4.1- and GFAP-positive protein levels in CA3 hippocampus. (G) Representative images of BBB endothelial cells stained with CD31 and p-MLKL in the CA3 regions and $(\mathrm{H})$ densitometric analysis of colocalized CD31- and p-MLKL-positive protein levels. Densitometry was semi-quantified using ImageJ software. Data represent the mean \pm SEM of values from three animals per treatment group. One-way ANONA; Bonferroni post hoc test vs. vehicle-treated mouse group; ${ }^{*} p<0.05,{ }^{\star \star} p<0.01,{ }^{\star \star \star} p<0.001$. 


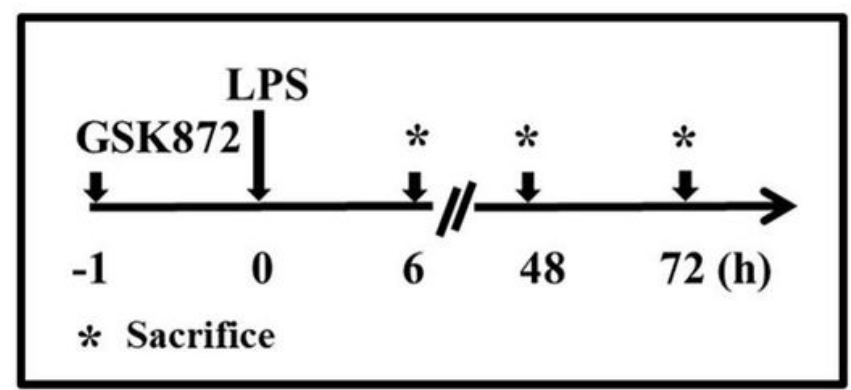

C

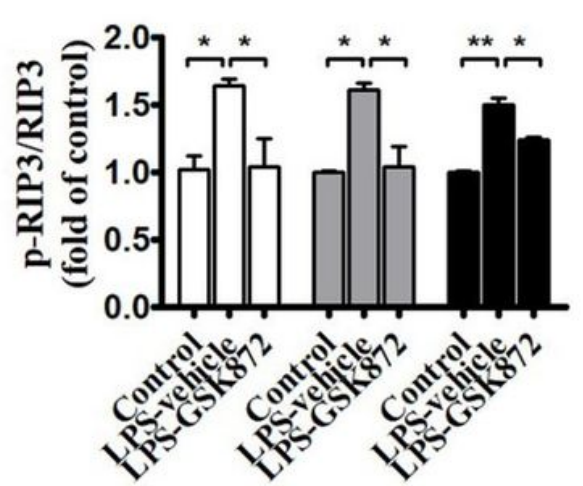

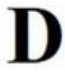
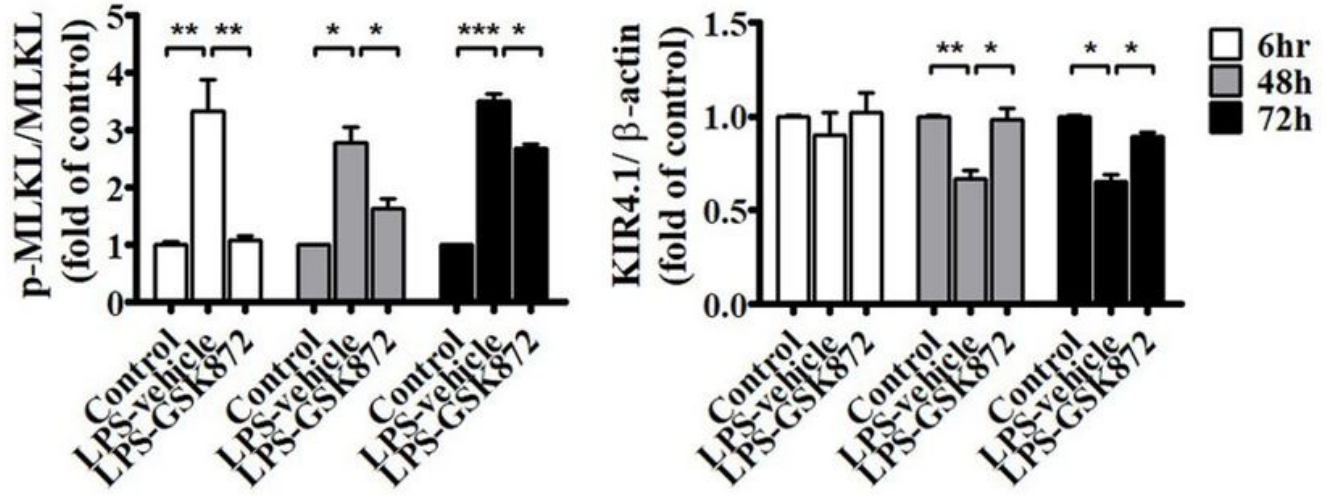

Figure 5

GSK872 suppressed RIP3-mediated necroptosis and restored Kir4.1 protein expression in mice within 3 days after LPS injection. (A) The experimental protocol. Mice were treated with GSK872 $(2 \mathrm{mg} / \mathrm{kg}$, i.p.) or vehicle (0.25\% DMSO) $1 \mathrm{~h}$ before $4 \mathrm{mg} / \mathrm{kg}$ LPS was given. The hippocampus was obtained to assess the protein levels at 6,48 , and $72 \mathrm{~h}$ after LPS injection ( $\mathrm{n}=3$ per group, each time point). The expression levels of p-RIP3, RIP3, p-MLKL, and MLKL detected RIP3-mediated necroptosis. (B) A representative Western blot showing the specific bands for these proteins and Kir4.1 protein. An equal amount of protein sample $(20 \mu \mathrm{g})$ obtained from the hippocampus homogenate was applied to each lane, and $\beta$-actin protein was used as the internal control. (C-E) Bar graphs showing the densitometric analysis of the molecules p-RIP3 and total RIP3 (C), p-MLKL and total MLKL (D), and Kir4.1 (E), normalized to total RIP3, total MLKL or $\beta$-actin expression, respectively. Each bar represents the mean $\pm \mathrm{SEM}$. One-way ANOVA; Bonferroni post hoc test vs. saline- and vehicle-treated groups or LPS- and vehicle-treated groups; ${ }^{*} \mathrm{p}<$ $0.05, * \star p<0.01$, and $* \star \star x p<0.001$. 

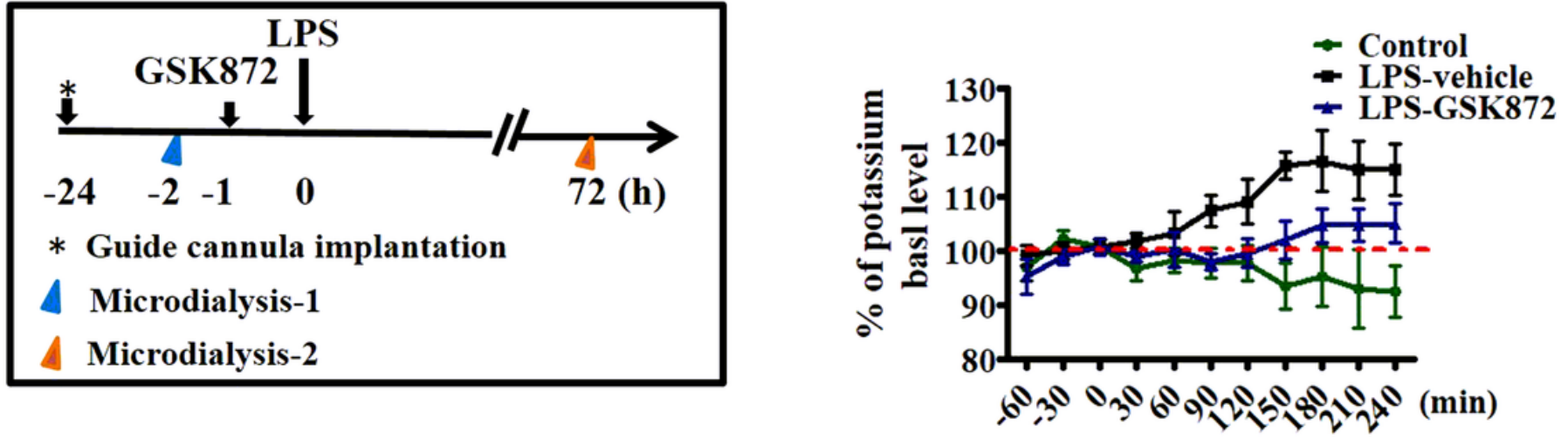

C

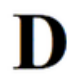

$\mathbf{E}$
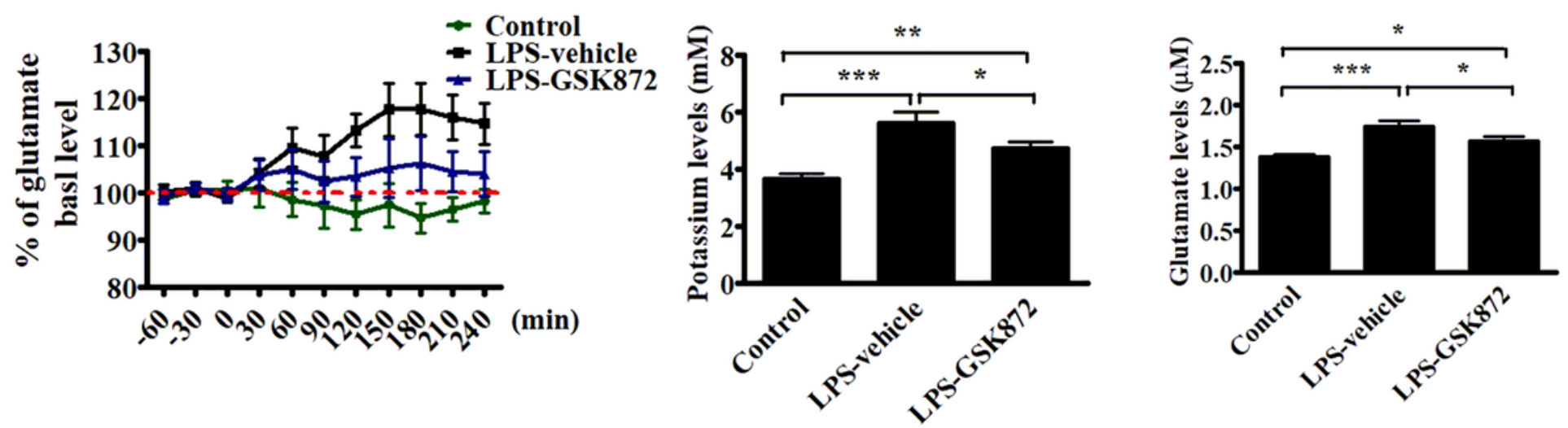

Figure 6

GSK872 attenuated the increased extracellular levels of potassium and glutamate in the hippocampus within $72 \mathrm{~h}$ after LPS injection. (A) The experimental protocol. One day after the chronic indwelling guide cannula was implanted in the hippocampus, mice were treated with GSK872 (2 mg/kg, i.p.) or vehicle ( $0.25 \%$ DMSO) $1 \mathrm{~h}$ before $4 \mathrm{mg} / \mathrm{kg}$ LPS was given. Microdialysis experiments were carried out $1 \mathrm{~h}$ before GSK872 injection. Samples were collected once every $30 \mathrm{~min}$ for $5 \mathrm{~h}$ from each mouse after $1 \mathrm{~h}$ stabilization, and the first three samples were defined as the basal levels (100\%). (B and C) The time course concentrations of extracellular potassium and glutamate in the hippocampus after GSK872 plus LPS treatment ( $\mathrm{n}=6$ per group). Data represent percentages (mean \pm standard error of the mean (SEM)) of values. Using two-way repeated measures ANOVA analysis, Bonferroni post hoc analysis revealed revealed that GSK872 significantly inhibited the increase in potassium levels $(F(1,110)=25.87, p<$ $0.0001)$ and glutamate levels $(F(1,110)=12.59, p=0.0006)$ induced by LPS given systemically. At $72 \mathrm{~h}$ after LPS injection, additional microdialysis experiments were performed in treated mice with sample collection once every $30 \mathrm{~min}$ for $2 \mathrm{~h}$ from each mouse after $1 \mathrm{~h}$ stabilization. (D and $\mathrm{E}$ ) Mean levels of extracellular potassium and glutamate in the hippocampus $72 \mathrm{~h}$ after LPS treatment ( $\mathrm{n}=6$ per group). 
Data represent the mean \pm SEM of values. One-way ANOVA; Bonferroni post hoc test; ${ }^{\star} p<0.05,{ }^{\star \star} p<0.01$, $\star \star \star p p<0.001$.

\section{Supplementary Files}

This is a list of supplementary files associated with this preprint. Click to download.

- sFig1.tif

- sFig2.tif 